\title{
ANALISA PERHITUNGAN BALLAST PADA PELUNCURAN MENYAMPING (SIDE LAUNCHING) KAPAL SUNGAI 200GT DI PT. DKB (PERSERO) CABANG SEMARANG
}

\author{
Zulfaidah Ariany \\ Program Studi Diploma III Teknik Perkapalan \\ Sekolah Vokasi Universitas Diponegoro
}

\begin{abstract}
Zulfaidah Ariany, in this paper explain that considering the risk faced in the side launching, limited land from the shipyard so that required calculation and analysis in the implementation of the launching. The purpose of this research is analyzes and counting ballast (a counterweight) used in a river boat lct 200 GT on the launching of sideways ( side launching) so that safe and floats can be perfect in water, as nown that the launching of is one of the stages important in the development process the new vessel which have prepared to be operated, formerly preceded by stage first cutting plate (cutting first steel plate) and the keel laying (laying ) keel of a ship. Before the handover of a vessel is carried, a ship will had some sea trial. The results of this research is scientific publication in national journal, as a input for the shipyard to implement the launch sideways safe as well as the basis for students and teachers included in matter basic lecture subjects of case in point in lecture the theory ship building .
\end{abstract}

Keywords: Launching; Side Launching; Ballast

\section{PENDAHULUAN}

Perkembangan ilmu dan teknologi yang semakin pesat dan seiring dengan perubahan zaman memicu perusahaan-perusahaan di bidang perkapalan untuk bisa bersaing menjadi yang terbaik, salah satunya yang dilakukan oleh PT. DKB (Persero) cab. Semarang yang memperoleh peluang untuk membangun kapal sungai type LCT.

Kapal sungai type LCT 200GT sedang dalam proses pembangunan oleh PT. DKB (Persero) cabang Semarang adalah milik Satuan Kerja Direktorat LLASDP Kementrian Perhubungan, kapal sungai perintis seri LCT-200GT ini adalah tipe pendarat untuk kendaraan dan penumpang yang akan digunakan dalam lintas penyebrangan perintis di sungai-sungai Papua khususnya sungai Mamberamu. Bagian haluan kapal ini dilengkapi dengan pintu pendarat dan digunakan sebagai tempat keluar-masuknya penumpang dan kendaraan, sementara bagian kiri dan kanan dibagian deck kendaraan dilengkapi dengan pintu untuk penumpang jika kapal melakukan sandar samping di tepi sungai.

Di beberapa galangan kapal di luar negeri seperti Polandia, membangun kapal kecil seperti AHTS, kapal penangkap ikan dan pengumpan kontainer, banyak menggunakan peluncuran samping, ini adalah metode dasar peluncuran. Peluncuran menyamping dilakukan karena alasan keamanan, dalam beberapa kasus, desain dan pusat desain kapal S.A diminta melakukan tes model peluncuran sisi untuk memperkirakan parameter dari gerakan lambung selama peluncuran. (kraskowski, 2012)
Pada tulisan ini, kapal yang dilakukan perhitungan adalah type kapal penumpang LCT pada perairan sungai-sungai di papua. Pemilihan tipe peluncuran menyamping karena keterbatasan lahan dari pihak galangan pembangun.

Peluncuran merupakan salah satu tahapan penting dalam proses pembangunan kapal baru yang sudah siap untuk dioperasikan, sebelumnya didahului oleh tahapan first cutting plat (pemotongan pertama pelat baja) dan keel laying (peletakan) lunas kapal. Sebelum serah terima kapal dilakukan, kapal akan menjalani sejumlah uji coba atau sea trial

\section{RUMUSAN MASALAH}

Mengingat akan sangat penting dan vitalnya perencanaan kegiatan peluncuran mendorong penulis untuk melakukan penelitian

Analisa perhitungan penempatan ballast dan persiapan peluncuran kapal sungai type LCT 200GT yang merupakan bangunan kapal baru oleh galangan PT. DKB (Persero) Cab. Semarang, analisa kondisi stop block, standing ways. Sliding ways, hingga di tentukan posisi ballast yang aman.

Tujuan penelitian ini adalah menganalisa dan menghitung ballast (penyeimbang) serta letaknya ditangki dasar ganda yang digunakan pada kapal sungai LCT 200GT ini pada kegiatan peluncuran menyamping (side launching) sehingga aman dan dapat mengapung sempurna di air.

Menjadi bahan-materi bagi pihak galangan untuk melaksanakan peluncuran menyamping yang aman.

Luaran dari penelitian ini adalah hasil analisa dan perhitungan jumlah volume ballast dan 
peletakannya pada kegiatan peluncuran menyamping (side launching).

Hasil penelitian ini akan diterbitkan dalam jurnal ilmiah nasional yaitu journal TEKNIK ini sebagai informasi bagi masyarakat, digunakan pihak galangan untuk diaplikasikan dalam kegiatan peluncuran sebagai bagian dari pembanguan sebuah kapal baru serta sebagai bahan untuk pengembangan penelitian lebih lanjut.

Hasil ini juga dimasukkan dalam materi perkuliahan (pokok bahasan contoh kasus) pada mata kuliah Teori Bangunan Kapal .

\section{METODE PENELITIAN}

Penelitian tentang analisa perhitungan ballast pada peluncuran menyamping (side launching) kapal sungai 200GT di PT. DKB (persero) cabang Semarang dilakukan dalam 3 (tiga) tahap. Ketiga tahapan tersebut adalah sebagai berikut :

- Pengamatan dan pengambilan data

- Perhitungan beban dan peluncuran

- Analisa peluncuran penyamping (Side Launching), pemodelan kegiatan peluncuran berdasarkan hasil perhitungan dan analisa yang telah dilakukan.

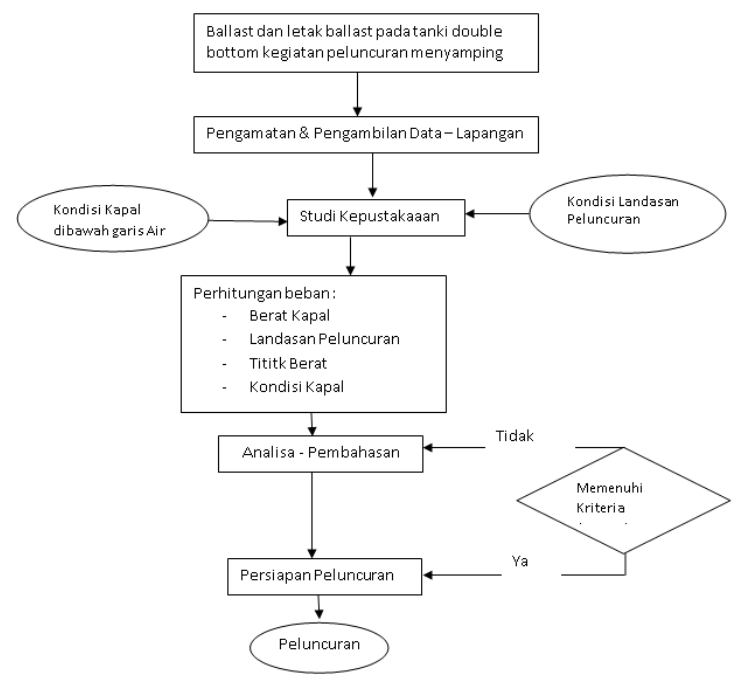

Gambar 1. Skema Penelitian

\section{HASIL DAN PEMBAHASAN}

Analisa Perhitungan Ballast Pada Peluncuran Menyamping (Side Launching) Kapal Sungai 200 GT Di PT. DKB (Persero) Cabang Semarang dimulai dengan mengetahui ukuran utama kapal. Ukuran utama kapal ini adalah:

Panjang Seluruh Kapal (LOA) :33,27 m

Panjang Antar Garis Tegak (LBP) :27,95 m

Lebar (B)

$9,00 \quad \mathrm{~m}$

Tinggi $(\mathrm{H})$

Sarat Air (T)

Kecepatan Dinas (V)

Berat Kapal (W)

$: 2,80 \quad \mathrm{~m}$

$2,00 \mathrm{~m}$

$: 10,0$ knot

$: 155,66$ ton

Pemeriksaan pondasi Stop Block
- Kekuatan Tanah :

Berat kapal + Ballast $\quad=155,66$ ton

- Beban tiap meter panjang (P')

$\mathrm{P}^{\prime}=(1,5 \mathrm{P}) /(0,9 \mathrm{LBP})=9,28$ ton

Pada jarak setiap $9 \mathrm{~m}$, jumlah stop block $=6$ buah

Jadi beban 1 (buah) stop block (Q) adalah ( 9 . P' )/6 $=9,28$ ton

- Beban Tanah

$\mathrm{F}=$ luas beton $=50 \times 50\left(\mathrm{~cm}^{2}\right)$

Beban tanah $=\mathrm{Q} / \mathrm{F}=3,172 \mathrm{~kg} / \mathrm{cm}^{2}$

Jumlah balok/ landasan luncur $=4$ buah

- Jarak antara balok luncur $= \pm 4 \mathrm{M}$

Beban 1 (satu ) balok/ landasan luncur (Q)

- $\mathrm{Q}=\mathrm{P}$ X 4 = $11.92 \mathrm{~T}$

Beban Tanah (W)

- $\mathrm{W}=\mathrm{Q} / \mathrm{P}=4.768 \mathrm{~kg} / \mathrm{m} 2$

Balok Luncur (Sliding Ways)

Berat Kapal + Ballast :155,66 Ton (P)

Jumlah Balok Luncur :5,5 Buah (n)

Lebar Balok Luncur :0.6 M $\quad$ (b)

Panjang Balok Luncur :16 M

Tegangan Tumpuan Balok Luncur

$\tilde{O} S=\frac{P}{n x b x l}=20.36 \frac{\text { Ton }}{M 2}$

Kecepatan pada jarak $9 \mathrm{~m}(\mathrm{Vf})$

$1 / 2 \mathrm{~m}(\mathrm{Vf} 2-\mathrm{Vo} 2)+\mathrm{MG}(\mathrm{H})-\mu \mathrm{FN}(\mathrm{S} / \operatorname{Cos} \mathrm{A})=0$

$\mathrm{Vf}=3.97 \mathrm{~m} / \mathrm{dt}$

Gaya luncur pada jarak $9 \mathrm{~m}(\mathrm{~F} 1)$

$1 / 2 \mathrm{~m}(\mathrm{Vf} 2-\mathrm{Vo} 2)+\mathrm{MG}(\mathrm{H})-\mu \mathrm{FN}(\mathrm{S} / \operatorname{Cos} \mathrm{A})=0$

$\mathrm{Vf}=13,513$ Ton

Slewing Moment

Jika moment R.1 + R.2 = moment R.3+R.4

\begin{tabular}{|c|c|c|}
\hline Berat kapal & $\mathrm{m}$ & 155,660 Ton \\
\hline Coef. Gesek dinamis & $\mathrm{u}$ & 0,015 \\
\hline Grafisitas & $\mathrm{g}$ & 9,810 \\
\hline Jarak luncur & $\mathrm{s}$ & $9,000 \mathrm{~m}$ \\
\hline Kecepatan pd ujung 1 & dasan & Vf \\
\hline Kecepatan awal & Vo & \\
\hline Tinggi awal peluncur & $\mathrm{h}$ & \\
\hline
\end{tabular}

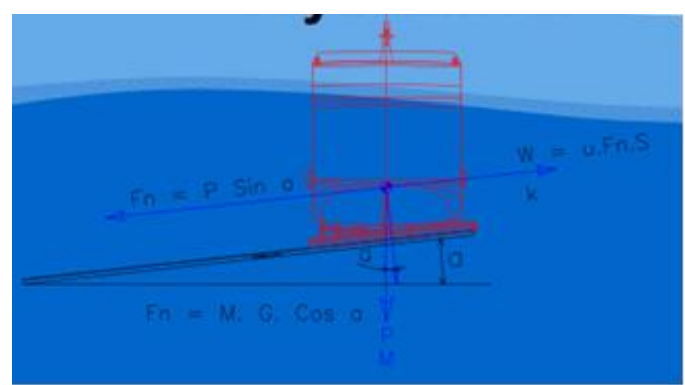

Gambar 2. Perhitungan landasan peluncuran.

Dengan perhitungan landasan peluncuran, kemudian disimulasikan peluncuran yang dapat dilakukan, terdapat 3 cara yang digaambarkan sebagai berikut: 


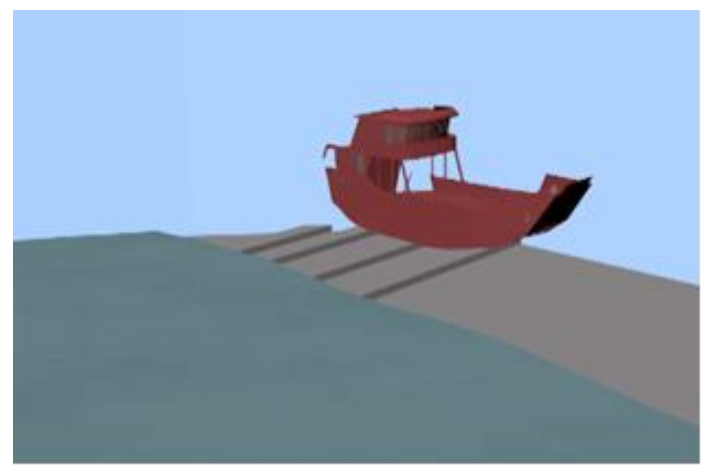

Gambar 3. Simulasi peluncuran 1

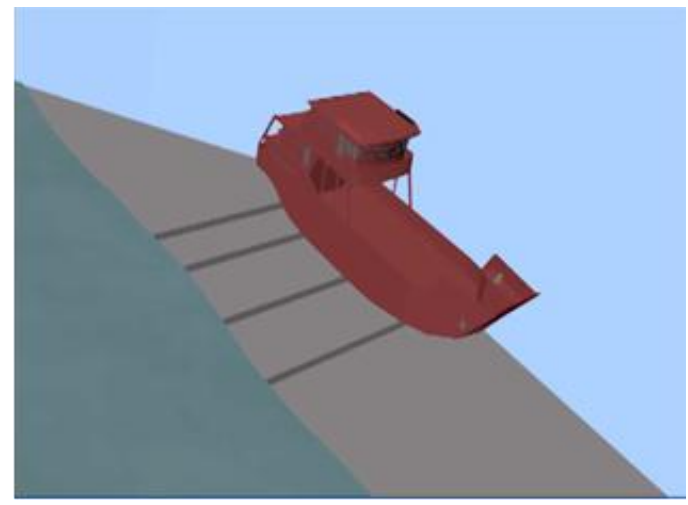

Gambar 4. Simulasi peluncuran 2

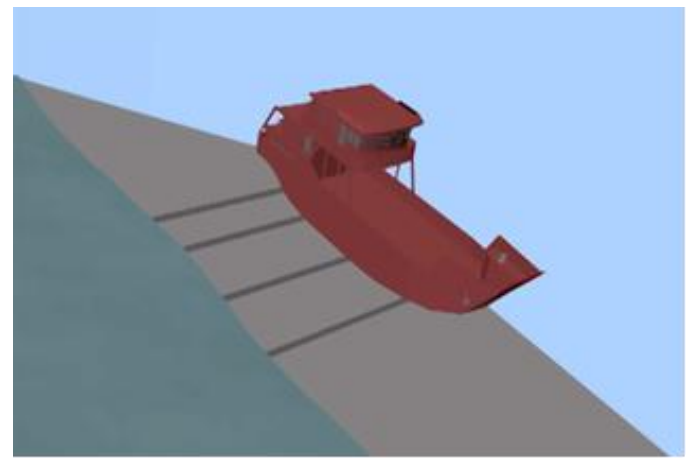

Gambar 5 Simulasi peluncuran $\mathbf{3}$

Kecepatan pada jarak $9 \mathrm{~m}(\mathrm{Vf})$

$1 / 2 \mathrm{~m}(\mathrm{Vf} 2-\mathrm{Vo} 2)+\mathrm{MG}(\mathrm{H})-\mu \mathrm{FN}(\mathrm{S} / \operatorname{Cos} \mathrm{A})=0$ $\mathrm{Vf}=3,397$

Gaya luncur pada jarak $9 \mathrm{~m}(\mathrm{~F} 1)$

$1 / 2 \mathrm{~m}(\mathrm{Vf} 2-\mathrm{Vo} 2)+\mathrm{MG}(\mathrm{H})-\mu \mathrm{FN}(\mathrm{S} / \operatorname{Cos} \mathrm{A})=0$ F. $1=13,513$ Ton

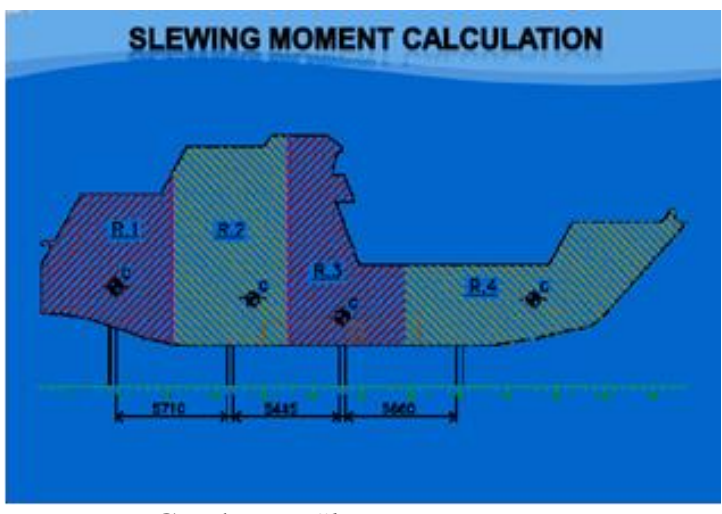

Gambar 6. Slewing Momen

Tabel 1. Slewing Moment Calculation

\begin{tabular}{|c|c|c|c|c|c|c|}
\hline No. & пеM & WEIGKT & V.C.G & L.C.G & M.V.CG & M.L.C.G \\
\hline 1 & rasko & 20241 & 2.924 & 2013 & $\ln .92$ & 57.416 \\
\hline 2 & Dirst GES. & 1000 & 1305 & 450 & 2152 & 76000 \\
\hline 3 & Mainss. & 0.000 & 1500 & 3.350 & 0.000 & 2.2500 \\
\hline 4 & INTESon & 2000 & 2950 & 2950 & 11060 & $9 . \mathrm{mo}^{\circ}$ \\
\hline & N.1 & 33.241 & 2.909 & 2.318 & 96.694 & 7.038 \\
\hline
\end{tabular}

Tabel 2. Penentuan Titik Tangki Ballast (1)

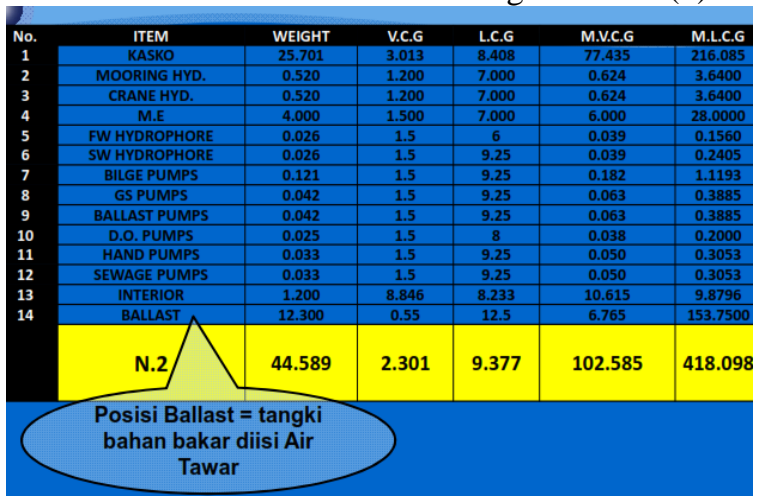

Tabel 3. Penentuan Titik Tangki Ballast (2)

\begin{tabular}{|c|c|c|c|c|c|c|}
\hline No. & ITEM & WEIGHT & v.c.G & L.C.G & M.V.C.G & M.L.C.G \\
\hline 1 & KASKO & 49.310 & 2.158 & 23.371 & 106.400 & 1152.434 \\
\hline 2 & ANCHOR & 1.140 & 3.422 & 28.545 & 3.901 & 32.541 \\
\hline 3 & ANCHOR & 0.190 & 3.422 & 28.545 & 0.650 & 5.424 \\
\hline \multirow[t]{2}{*}{4} & ANCHOR CHAIN & 3.708 & 3.422 & 28.545 & 12.689 & 105.844 \\
\hline & N.3 & 54.348 & 2.275 & 23.851 & 123.639 & 1296.243 \\
\hline \multirow{6}{*}{$\begin{array}{c}\text { No. } \\
1 \\
2 \\
3 \\
4\end{array}$} & ITEM & WEIGHT & v.c.G & L.C.G & M.V.C.G & M.L.C.G \\
\hline & KASKO & 49.310 & 2.158 & 23.371 & 106.400 & 1152.434 \\
\hline & ANCHOR & 1.140 & 3.422 & 28.545 & 3.901 & 32.541 \\
\hline & ANCHOR & 0.190 & 3.422 & 28.545 & 0.650 & 5.424 \\
\hline & ANCHOR CHAIN & 3.708 & 3.422 & 28.545 & 12.689 & 105.844 \\
\hline & N.4 & 54.348 & 2.275 & 23.851 & 123.639 & 1296.243 \\
\hline
\end{tabular}


Tabel 4.Friction factor dinamis $(\mathrm{FD})=0,02=(\mathrm{W}+$ Weight of sliding) cos a

\begin{tabular}{|lll|l|l|}
\hline $\begin{array}{l}\text { Length of } \\
\text { way } 1\end{array}$ & sliding & 1 & $=4,357991345$ ton/ $/ \mathrm{M}^{2}$ \\
\hline $\begin{array}{l}\text { Length of } \\
\text { way } 2\end{array}$ & sliding & 2 & $=5.823683793$ ton/ $/ \mathrm{M}^{2}$ \\
\hline $\begin{array}{l}\text { Length of } \\
\text { way } 3\end{array}$ & sliding & 3 & $=3,096811181$ ton $/ \mathrm{M}^{2}$ \\
\hline $\begin{array}{l}\text { Length of } \\
\text { way } 4\end{array}$ & sliding & 4 & $=7,084145799$ ton $/ \mathrm{M}^{2}$ \\
\hline
\end{tabular}

$$
\begin{array}{ll}
\text { Cos } \alpha & =0,9945 \\
\text { Length of sliding way } & =22 \mathrm{~m} \\
\text { Wide of sliding way } & =0,35 \mathrm{~m}
\end{array}
$$

Tabel 5. Launcing Force $(\mathrm{N})=(\mathrm{W}+$ Weight of sliding). Sin)-F

\begin{tabular}{|l|l|}
\hline F.1 & $=0.681076$ Ton \\
\hline F.2 & $=0.906793$ Ton \\
\hline F.3 & $=0.486854$ Ton \\
\hline F.4 & $=1.100904$ Ton \\
\hline$\sum F$ & $=3.175626$ Ton \\
\hline
\end{tabular}

\begin{tabular}{|l|l|}
\hline $\sin \alpha$ & $=0.104529$ Ton \\
\hline N.1 & $=2.898123$ Ton \\
\hline N.2 & $=3.858595$ Ton \\
\hline N.3 & $=2.07668$ Ton \\
\hline N.4 & $=4.684558$ Ton \\
\hline$\sum F$ & $=13.51297$ Ton \\
\hline
\end{tabular}

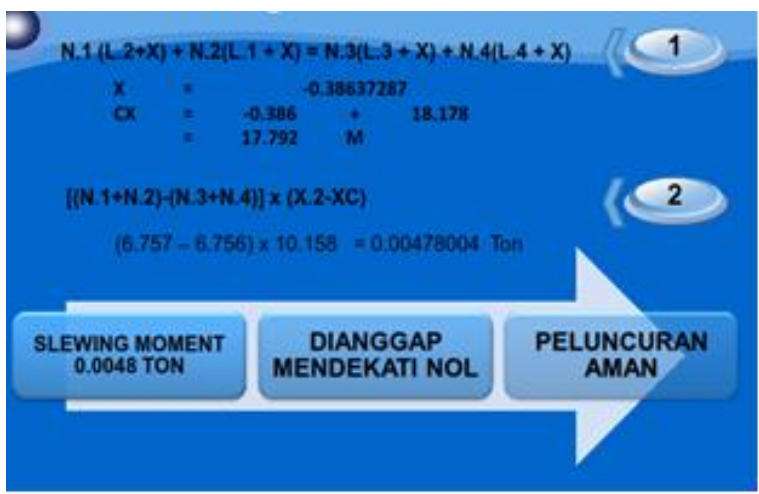

Gambar 7. Analisa peluncuran akan aman dilakukan

\section{HASIL DAN PEMBAHASAN}

Kegiatan peluncuran telah dilakukan dengn hasil sukses dan lancar tanpa kendala apapun, dilakukan pada malam hari, mengikuti waktu pasang-surut air.

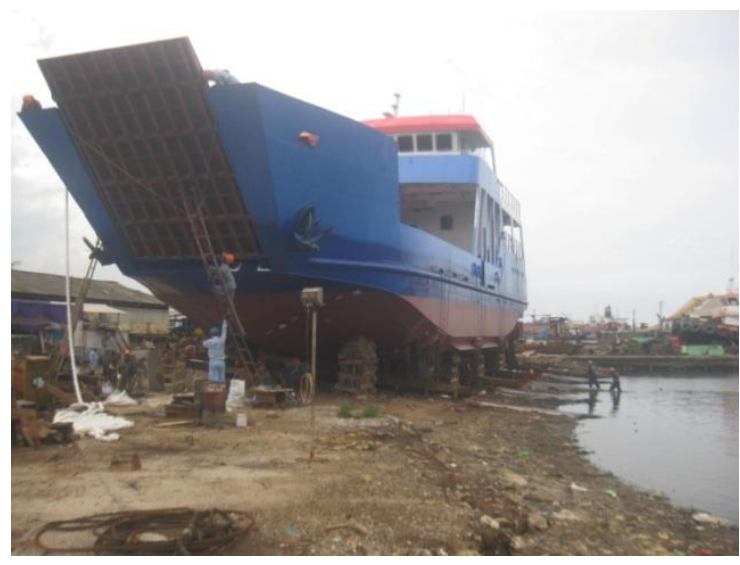

Gambar 8. Persiapan kapal melakukan peluncuran

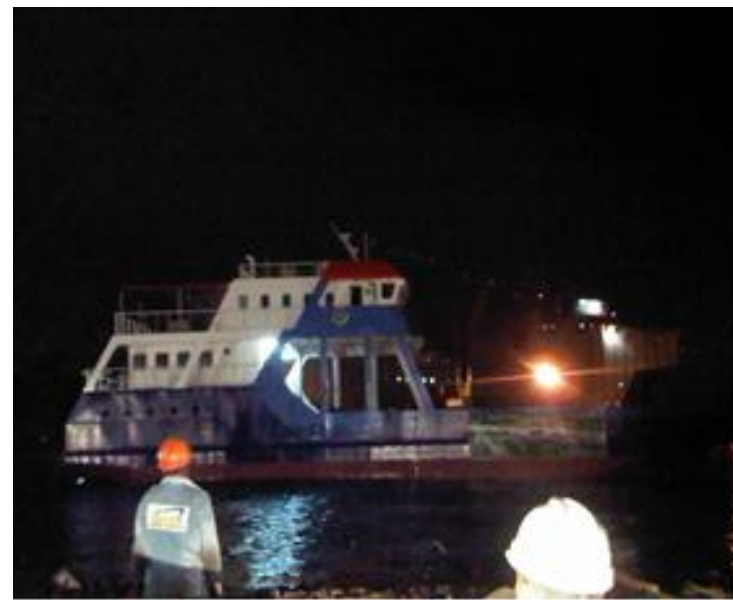

Gambar 9. Kapal dalam kegiatan peluncuran

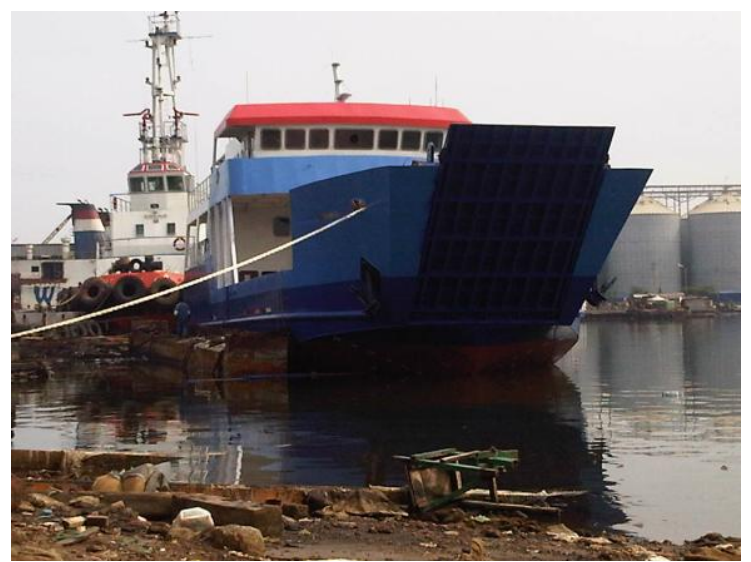

Gambar 10. Kapal setelah peluncuran 


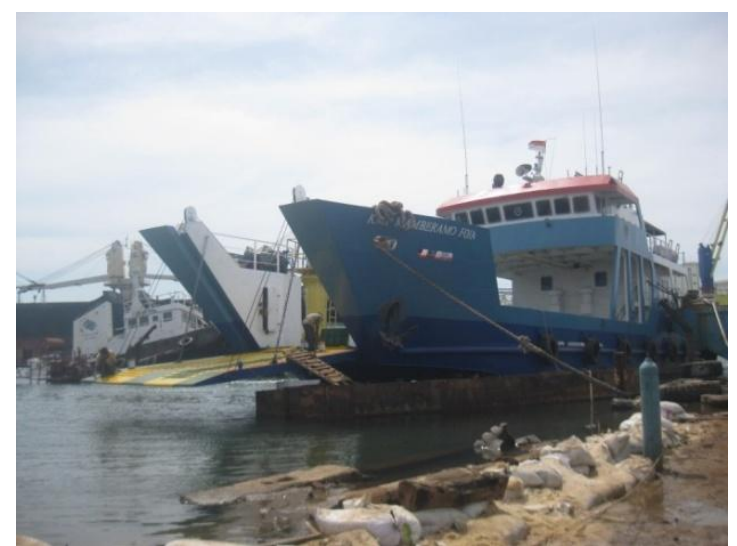

Gambar 11. Kondisi bangunan kapal terkini

\section{KESIMPULAN}

Berdasarkan hasil perhitungan dan analisa maka posisi ballast yang harus diisi pada aat peluncuran menyamping adalah posisi tangki bahan bakar yang di isi dengan air tawar, pada gading 30 hingga 36 posisi port - starboard (kiri dan kanan kapal)

Slewing moment (moment ayun) yang dihasilkan dari perhitungan dan analisa dihasilkan adalah 0,008 ton di anggap mendekati angka 0 sehingga analisa slewing moment bahwa peluncuran yang di lakukan aman.

Kegiatan peluncuran dengan posisi menyamping telah dilakukan pada kapal sungai type LCT dengan menggunakan perhitungan dan analisa yang telah dilakukan dengan hasil peluncuran aman, terkendali, sesuai dengan yang diharapkan.

\section{SARAN}

Banyak hal yang perlu diperhatikan pada kegiatan pembangunan kapal baru, kegiatan peluncuran hanya merupakan sebagian hal kecil, penelitian, perhitungan dan analisa lebih lanjut dan akurat dapat mendorong akurasi waktu pembangunan dan penghematan biaya yang di keluarkan.

Metode terbaru dan telah banyak diterapkan di berbagai galangan adalah penggunaan balon udara (air bag) pada kegiatan peluncuran, docking maupun undocking pada kapal-kapal reparasi.

Ucapan Terima Kasih. Disampaikan kepada semau pihak yang membantu pelaksanaan dan penyelesaian penelitian ini, terutama kepada tim galangan PT.DKB. Terima kasih juga dihaturkan kepada Rektor Undip dan Sekolah Vokasi yang membantu pembiayaan selama penulisan dan penyelesaian penelitian ini.

\section{DAFTAR PUSTAKA}

1. Edward V.Lewis, 1988, Principle of Naval Architecture, Second Revision, SNAME.

2. Kraskowski.M, 2007, Simplified RANSE simulation of a side launching, Archives of Civil and Mechanical Engineering Volume 7, Issue 3, Pages 151-159

3. Ship Design and Research Centre S.A., Ship Hydromechanics Division, Szczecińska 65, 80-392 Gdańsk

4. Syamsul Asri, 2000, Stabilitas Kapal, Kerjasama Segitiga Biru ITS-UNHASUNPATTI Jurusan Perkapalan, Fak. Teknik, Unhas 